\title{
The Cosmological Divergent Proliferation in FEYERABEND'S PLURALISM
}

\author{
Deivide Garcia da Silva Oliveira \\ Federal University of Reconcavo of Bahia (UFRB), BRAZIL \\ deividegso@gmail.com
}

\begin{abstract}
In this paper, I argue that Feyerabendian proliferation is best understood as cosmologically divergent proliferation. The divergent aspect is inspired by a Darwinian background, and it affects other elements of Feyerabend's philosophy, as much as the way his pluralism advances, like the cosmological dimension. This cosmological item influences not only how theories should proliferate - divergently - but also why they must be tenaciously retained and compared. On this account, we underline Feyerabend's view that the principle of proliferation is never alone; instead, it is always coupled with the principle of tenacity. This is the reason we take these two principles as two sides of the same coin. Moreover, when approaching tenacity, we discuss three aspects of tenacity (attractiveness, fruitfulness, and retainment) under two forms of how they are related to the cosmologically divergent proliferation. First, working on many cosmologies, allowed by proliferation, to develop them. Second, retaining all theories by what we name as the practical suspension or setback. As a result, we argue that such an approach, divergent pluralism, is an adequate way for understanding Feyerabend's pluralism and a clear way of avoiding misunderstandings of his view.
\end{abstract}

Keywords: cosmological divergent proliferation $\bullet$ theory suspension $\bullet$ tenacity $\bullet$ darwinism

\section{Introduction}

Feyerabend died in 1994, and the last edition of the book Against Method during his lifetime was printed in 1993. The first version of this book was a paper released in 1970. Since 1970, there have been many attempts to define Feyerabend's pluralism, and his philosophy has been interpreted in various forms. It seems as if Feyerabend became a victim of his pluralism (Athanasopoulos 1994; Brown 2016; Bschir 2015; Butts 1966; Farrell 2003; Giere 2016; Heller 2016; Lloyd 1997; Neto 1991; Oberheim 2012 [2006]; Preston 1997; Shaw 2016; Tambolo 2007).

All these interpretations had some achievements. Progress has been made concerning the kind of pluralism Feyerabend adopted, once he made his view clearer by answering some criticisms since the release of the first edition of Against Method. As a result, most of Feyerabend scholars accepted a larger presence of ontological 
dimensions in Feyerabend's pluralism, that is, a pluralism concerned not only with methods and theories, but also with other things like ontologies and cosmologies.

Despite of these recent achievements respect ontologies and cosmologies, such an expanded conception of pluralism where Feyerabend affirms the fundamental predominance of cosmologies over theories or methods (Paul Feyerabend 1981d) can be seen before Against Method (1993). Notwithstanding, that larger presence of ontologies and cosmologies was expanded with the last edition of Against Method, and deepened with the publication of book The Conquest of Abundance (1999) along with the republished papers in it highlighting the role of cosmology in his philosophy, such as "Potentially every culture is all culture" (Feyerabend 1999 [1994]). This dimension has not escaped the commentaries of Feyerabend scholars (Benvenuto 1995; Brown 2016; Munévar 2002).

Be that as it may, no clear-cut definition of cosmological dimension that constitutes the central aspect of his pluralism, especially the principle of proliferation, followed the increase of interest in such a dimension. For this lack, our aim is to offer a better view on that dimension. We will argue that the best way to understand Feyerabend's pluralism is through the principles of proliferation-tenacity. We will do this from a pluralist cosmological fashion.

Accordingly, we are going to bring to light the basis of Feyerabend's principles of proliferation and tenacity. We will focus on the divergence, competition, and on what we are calling practical setback aspects as being fundamental to Feyerabend's conceptions of proliferation and tenacity. For this reason, we propose to use the notion of divergent pluralism to refer to these aspects of Feyerabend's pluralism.

According to divergent pluralism, we need to proliferate our universal theories not in a convergent way, but in a divergent fashion ${ }^{1}$ (1965b, p.107). There are several reasons for this need, from discovery to justification, as well as for humanitarian reasons. It is also important to do this because the more we clarify Feyerabend's pluralism, the easier it will be to reintroduce Feyerabend's pluralism within the landscape of contemporary debates in philosophy of science concerning pluralism and the relationships that contemporary pluralisms have with Feyerabend's.

For instance, is there any chance to establish a dialogue between our proposal of Feyerabend's divergent pluralism and the conception, supported by Ruphy, that a minimal starting point shared by pluralists "is the claim that the representations delivered by science are partial, contingent, and nonconvergent" (2017, p.82)? We believe so, especially because Ruphy's "foliated pluralism" (2011 2017), also deals with a form of "ontological enrichment", although based on Hacking's plurality of styles of scientific reasoning.

The idea of ontological enrichment is also germane to our debate. Therefore, it can give us another point of comparison to other pluralisms, progress of knowledge, procedures and interests (Ruphy 2011, p.1212; 2017, p.xvi). 
From these examples, we intend to make clear that our proposal opens many possibilities of dialogues with Feyerabend's pluralism, expanding the road that relates it with more recent formulations of pluralisms, such as Convergent pluralism (Goertzen 2007), Pluralism of hypotheses (Pepper 1942), Popperian ontological pluralism (Popper 1972), Compatible pluralism (Bailer-Jones 2000), Integrative pluralism (Mitchell 2002), Nomological metaphysical pluralism (Cartwright 1999), Chang's active normative pluralism (2012), and so on.

That being said, it was pointed out by Farrell (2003) that when one calls Feyerabend's pluralism 'anarchism', it just adds fuel to the fire of misunderstandings, driving our attention towards secondary or nonexistent aspects of his pluralism, such as 'anything goes' ${ }^{2}$. Moreover, a outermost consequence is that without an adequate and clear message of what kind of pluralism Feyerabend embraces, his philosophy would not have enough space for full development. It would suffer from the symptoms that Feyerabend described in his principles of proliferation-tenacity, ${ }^{3}$ that is, underdevelopment and elimination. ${ }^{4}$

\section{The cosmological element inside the principle of proliferation}

We will argue that Feyerabend advocates for the proliferation of alternatives, which is always coupled with tenacity (Feyerabend 1981 [1970], 1999 [1968]), and that he was thinking about proliferation of alternatives from a cosmological and divergent viewpoint. We can see it with special distinction in two passages of the third edition of Against Method (1993, pp.33, 270). The basic starting point, shown in many of Feyerabend's texts, is that theories should be contrasted with other theories, not with facts (1962, 1969, 1981 [1970], 1993, 1999 [1961], 1999 [1968]).

Moreover, in a clear reference to the principles of proliferation and tenacity, in Against Method (1993), Feyerabend claims that we should look for "incompatible alternatives" even before the status quo shows its weaknesses (1993, p.33). This claim is a procedure that asks not only for looking alternatives, but for incompatible ones, particularly the ones that are "fully fledged alternative cosmologies", so that they have the opportunity to modify or "even to replace, the 'scientific' cosmologies of a given period" (1993, p.33, fn. 1). But how does this happen? He answers, in a clear reference to two aspects of tenacity — comparison and raise or develop (1981 [1970], pp.143-44 $)^{5}$ - is that we should "compare theories with other theories" and "try to improve rather than discard the views" defeated in competition (1993, p.33). In a few words, resulting in a tenaciously critical competition.

However, let us take a step back to better understand the principles of proliferationtenacity. In simple terms, theoretical proliferation is just the proliferation of theories, 
so it does not mean the proliferation of cosmologies. This suggests, as well observed by one of our reviewers, that Feyerabend's proliferation is not just about cosmologies (non-instantiated, i.e., universal theories), but also implications for lower level and auxiliary theories, i.e., in his or her words - micro disagreements. We agree with the reviewer, only that micro disagreements do not seem to concern Feyerabend as much as upper level theories. For instance, one could accept a geocentric worldview but reject Ptolemaic astronomic system. Tycho Brahe did this. He combined parts of the Copernican system with the Ptolemaic system to create his own system, the Tychonic system. In this case, there was proliferation of theories, but Tycho's and Ptolemy's theories were operating within the Geocentric ontology despite their different auxiliary theories. Huxley, also, did the same. From inside an evolutionary worldview, he argued for his version of evolutionary theory, which was not in agreement with the Darwinian mechanism of natural selection (Ruse, 1999). In a way, Asa Gray did something similar to Huxley. Gray, who was a Darwinian, said that natural selection was not powerful enough to produce variations, which should be supported by divine guidance (Richards \& Ruse 2016, p.76).

Actually, most of the criticism against Feyerabend only sees lower-level theoretical proliferation without tenacity. However, we propose that the mere proliferation of theories can happen without cosmological proliferation, but not as the main concern in Feyerabend's principle of proliferation. Why not? Because dealing with the epistemic, ontological, linguistic and practical problems involving a theory is something that presupposes familiarity, commitment, even tacitly. Hence, the survival of old theories depends on that familiarity and commitment, which is a problem for a proposition that suggest the contrast between theories, not between theories and facts. Therefore, the only way to do progress knowledge under this proposition is to promoting a rich proliferation in a divergent and critically sharp way, that is, by introducing cosmological alternatives.

Cosmological theories, then, are rooted in an ontological dimension, bringing up all kinds of implications to every aspect of our realities and forms of knowledge. However, cosmological alternatives are not a logical necessity for the development of knowledge, and, as Feyerabend said referring to the Copernican and Ptolemaic theories as not incommensurable, neither they do need to be incommensurable (1975, p.114). Empirically, astronomy was not in crisis, "Copernicus thought the Ptolemaic system to be empirically adequate - he criticized it for theoretical reasons. And his 'observations' are essentially those of Ptolemy, as he says himself" (1993, p.145). Despite this, even for the epistemic and psychological effects that a cosmology brings upon us, such as so-called natural interpretations, it would be more effective if these cosmological alternatives were incommensurable. In other words, they are clearly two different items of Feyerabend's pluralism. ${ }^{6}$

The reason of that efficiency is because we cannot escape from the fact that even 
our perception of a phenomenon is shaped by a "'grammar' [that] contains a cosmology, a comprehensive view of the world, of society, of the situation of man which influences thought, behaviour, perception" (1993, p.164, brackets added). Such a grammar goes beyond theoretical conflicts of epistemic concepts. Such a cosmology goes beyond epistemology. It touches morality, shaping an approach and creating patterns of resistance "to widely divergent points of view' that could evolve to "instances of incommensurability" (1993, p.165, italics added). There could exist divergent theories without incommensurable disputes. Incommensurable theories do not need ontology, but they can carry their own ontology. When they do carry it, then "worldviews [that] interact with Being in a mutually creating fashion", affect and shape "reality" (1999, p.xi, brackets added) in a peaceful process of conflicts and competition, between new and old views (1993, p.227).

Still, proliferation does not have to be incommensurable, although when it is, it reveals an ocean of anomalies, advancing our understanding of rationality of science, and more specifically, in critical debate with the status quo (1993, p.150). In an enlightened fragment, he says that science is plural and that "its plurality is not coherent, it is full of conflict" (1999, p.239). These plural accounts, in many cases, are so widely different that they "find facts that conform to their categories (and are therefore incommensurable with the facts that emerge from different approaches) and laws that bring order to assemblies of facts of this kind." (1999, p.239). Of course, that does not entail any necessary rupture of possible understanding between the new and the older faith (1993 1999). Incommensurability, Feyerabend remembers, is a concern for philosophers, not for scientists (1993).

In "Consolations for the specialist", the principles of proliferation-tenacity are described as "an essential feature of the actual development of science" (1981 [1970], p.142), despite they do not seem to have been taken from the cosmological approach at the time (1981 [1970]). Feyerabend gradually realized that his proposal touched a deeper problem of theories, the ontological one (Preston, 2020), and many basilar aspects of this deeper relation which were always present, developed, and changed.

Why is that the case? Because by definition proliferation "means that there is no need to suppress even the most outlandish product of the human brain" (Feyerabend 1981 [1970], p.143). That is, we should keep inventing new alternatives in a way that could result in the development of new 'realities'. In addition, when we couple our interpretation of proliferation with the definition of tenacity, which recommends to retain ideas, but only "to develop them further, to raise them with the help of criticism" (1981 [1970], pp.143-44), the consequence, always within an ongoing research viewpoint, is that sooner or later we will touch the ontological aspects of our theories. All of this is part of the reason, as well as a realist position, ${ }^{7}$ that allows a perspective where Feyerabend ends up supporting his own form of "ontological pluralism" (1999, p.215). 
Therefore, proliferation of mere theories is necessary but not enough (1981e, p.67), since the mere proliferation of theories does not inevitably mean the competition new worldviews and forms of life, as much as source of external criticism and distance from the mainstream theory. And that is the primary purpose of proliferation. Quoting J.S. Mill's On Liberty, Feyerabend reminds the reader that proliferation is not firstly proposed to solve epistemological or methodological disputes. Rather it is introduced "as the solution to a problem of life: how can we achieve full consciousness; how can we learn what we are capable of doing; how can we increase our freedom so that we are able to decide [...]?” (1981e, p.67). In order to do that, the better way is by increasing not only the plurality of theories, but also getting in contact with plural and different worldviews and epistemologies, even if they appear to be illusions (1999, p.268). This is part of the inglorious duty of pluralists, to investigate the truth by contesting it, even when it seems absurd, so "if opponents of all-important truths do not exist, it is indispensable to imagine them" (1981e, p.69), as a form of opening a path to testing different forms of life and human existence (1981e, p.69, fn. 6).

Feyerabend's proliferation gradually switches the focus from an epistemic to a cosmological aspect. By cosmology, he means basically an account of everything that there is in its reality, at a fundamental level (1965b). For instance, by and large, Parmenides's view which can be described in terms of "cosmological stories" in a way that permeates all levels of his philosophy (1999, p.87). As a result of the overt and covert influence that cosmologies develop over the study of phenomena are many, like the automatic exclusion of some problems or entities from their range of scope. For instance, the explanation of particles or fields in science, like gravitational fields, cannot be posed side by side with religious entities. The reason, the defenders of science reply, is "because Gods do not fit into a scientific worldview" (1999, p.134), and from that approach, religious and scientific views have different cosmologies, just like Copernicus and Geocentrism have different cosmologies (1993, p.112).

The same idea of competition between scientific and nonscientific cosmologies can also be applied in a more specific fashion, from inside the scientific worldview. It depends only on what two or more cosmologies of scientific theories understand and explain our world, or concrete problem. The result could drastically change our whole worldview, even outside scientific limits. Theories can introduce particular ways to posit what underlies our reality, as Newtonian theory and the impetus theory (1962, p.78), or the Newtonian and Quantum mechanics (1993, pp.207,212), or evolutionary and non-evolutionary theories do. In all these cases, the theories actually propose basic structural changes to our worldview. Of course, sometimes fundamentally different cosmologies may share a portion of facts, a "partial agreement" of evidences (1993, p 118). However, this does not make those facts stable, fixed, above the theories, and neither it does make those theories our only options, or even true options. 
Feyerabend does not give to the scientific worldview any form of a priori precedence over non-scientific traditions as well. Science "certainly is not the only source of reliable ontological information" (1999, p.145). As an example, he compares this divergent plurality of cosmologies with a supermarket and its abundance of products. He says that sciences, arts, and religion offer us supermarkets which, by widely different individual inclinations and occasional conflicting stages, allows each culture to evolve, reaching maturity concerning problems and ways to deal with them (2011, p.9; Preston 2000). In other words, this supermarket issue, which we take to be in relation with divergent proliferation, expands our debate to more than just theories. It shows how theories may carry their own worldview, connecting the worldview with the problem of incommensurable theories and the benefits resulting from them, when we investigate basic matters (1993).

The underlying reason for this, we claim, is because Feyerabend was much more interested in a specific kind of proliferation, that is, the cosmological one (1993, pp.33, 52, 113; 1999, p.231). Technically, cosmological theories are a particular kind of theory. Cosmological theories are universal theories, whether scientific or not. For instance, outside science, the Iliad and the Bible are instances of fully fledged cosmological theories.

When Feyerabend mentions universal theories, he is not referring to any form of logical universality like 'all ravens are black'. The reason for this is simply that such universality, despite its efforts to say something about all ravens, falls short of Feyerabend's idea of cosmology. A universal theory does need to say a word about everything that there is, which does not happen in the example of black ravens (1965b, p.224, fn.5). To say that all ravens are black does not say a word about our mental states, cultural existence, it does not "include myths, political ideas, religious systems" (1965b, p.224, fn.5), neither does it favour competition from a cosmological viewpoint.

Furthermore, the notion of cosmological theories recommend a step back from natural interpretations within their domains. However, due to their universality and their implications, they not rarely inform us about "at least some aspects of everything there is" (1965b, p.224, fn.5). For instance, Newton's mechanics or Darwin's evolutionism, despite their specificities in their domains, also had impacts on many other domains. Beyond their specific fields, due to the cosmological character touching basically some aspect of everything that there is, it is not surprising that these theories ended up engaging in incommensurable disputes, from inside and outside their scientific field. The extension of effects and changes promoted by them respect our theoretical entities, perception, grammar, thoughts, even culture and religion, correspond to the very ground where some of scientific fundaments rest. So, as we will see, though theories do not need to be incommensurable, when a theory proposes a worldview which suspends the universal principles of its rivals, and by this 
"all facts and all concepts" (1993, p.205), then we most likely have a case of incommensurability.

This remarkable aspect of this notion proliferation of divergent cosmologies is an answer to the fact that if we are living within a specific reality, we are usually not aware of it or its limitations. As Feyerabend said, "we recognize their effects only when we encounter an entirely different cosmology: prejudices are found by contrast, not by analysis." (1993, p.22). Moreover, science is not freed from this problem, so the scientist's "most sublime theories and his most sophisticated techniques included, is structured in exactly the same way." (1993, p.22).

Divergent proliferation understands that science is composed of many epistemologies that carry cosmologies, reflecting the ontological pluralism to which there is "not a single scenario called 'the world' or 'being' or 'reality' but a variety of responses" to a variety of realities (Paul Feyerabend 1993, pp.270-72), and catching up with this is how science has historically advanced knowledge. That is also the reason that, besides proliferation, tenacity recommends us to "retain the new cosmology until it has been supplemented by the necessary auxiliary sciences" (1993, p.113).

On a specific topic, like scientific knowledge, his proliferation of cosmologies was concerned with the way scientists conceive the world when dealing with concrete cases and allowing each universal theory the chance to evolve. Putting divergent cosmologies into competition avoids any forms of reductionism in advance. The ontological status of such theories allows them to "share too many assumptions", which also help us to see that cosmological proliferation is more than just proliferation of inconsistencies ${ }^{8}$ (Farrell 2003, p.89).

\section{On details of Proliferation}

In order to keep ourselves focused on our aim, that is, Feyerabend's divergent proliferation, let us jump into the elements that constitute this principle. For analytical purposes, we will separate the inseparable pair, tenacity and proliferation. But we will return to tenacity in section $4 .^{9}$

To begin with, we could ask about the reasons that Feyerabend's pluralism presumes the need to keep up proliferating new theories regardless anything. What proliferation in fact means? For instance, does indeed proliferation demand only the proliferation of new theories? Not necessarily. We could not only invent new theories, but revive old ones (1981c, p.ix; 1981 [1970], p.144). However, how and why should we do that? What are the benefits of it? Should all theories converge, diverge, be compatible, or consistent? How, why, or when throughout the stages of scientific research, could we proliferate?

The current interpretation of Feyerabend offers answers to at least some of those 
questions, though not as clearly as we would like. We argue that based on Feyerabend's ontological pluralism, he assumed a divergent pluralism concerning cosmological proliferation. To do this, he derived his inspiration from Darwin's Principle of Divergence. Without an understanding of this relation between Darwin's principle and Feyerabend's divergent proliferation, hardly there can be a full appreciation of Feyerabend's pluralism. ${ }^{10}$

Moreover, divergent proliferation must be seen as a permanent feature of all stages of research. Given our limitations as human beings, to keep the research in movement, avoiding stagnation of our species, is better than supposing that we have reached the truth. Moreover, Feyerabend specified concrete elements that allow the test, criticism, and enhancement of existing theories. Thus, for reasons that will become clear below, we suggest that Feyerabend's pluralism should be labeled, for short, cosmologically divergent pluralism. ${ }^{11}$ Notwithstanding, a more exact name for its elements would be a cosmologically divergent-competitive practically setback pluralism, which generally reflects the features of the principles of proliferation-tenacity in his pluralism.

\subsection{Cosmologically divergent-competitive pluralism}

Let us first explain the divergent-competitive element of Feyerabend's pluralist cosmology: the aspect of proliferation in the principle of proliferation-tenacity.

The notion of divergence generally refers to a process of moving in a variety of directions. It is often contrasted with the general form convergent pluralism. The latter case, although starting from a plurality of views, it seeks to converge them, looking for some kind of unity. For instance, the passage from the revolutionary stage to that of normal science in Kuhn's philosophy could be seen as a form of pluralist convergence. Whereas in Kuhn's view pluralism can reach its maximum potential in revolutionary periods, Feyerabend thinks that pluralism is present in any and all stages of knowledge, especially because there would not be such a thing as normal science.

Thus, Feyerabend's divergent proliferation seems to be primarily interested in contrasting universal theories, i.e., fundamentally conflicting views. As one of our reviewers pointed out, Feyerabend says that cosmologically distinct theories are the sharpest means of criticism (1965a 1975).

We agree with him or her. This is because cosmologically distinct theories could raise a form of contrast outside the fundamental principles of the mainstream theory. For instance, The contrast between experience and theory "works well with theories of low degree of generality whose principles do not touch the principles on which the ontology of the chosen observation language is based." (1965a, p.214). This form of contrast assumes as a starting point a "background theory of greater generality" (1965a, p.214), so no fundamental principle is violated. 
Conversely, a contrast of a cosmological theories carries with it a sharper criticism about the ontological basis of that mainstream theory, and maybe of the general knowledge in itself. As we already said, this theoretical contrast, by definition, carries a promising form of inconsistent worldviews, "containing a new view of man and of his capacities of knowing", of older ideas and sensations (1993, p.112).

Proliferation of that cosmological alternatives "will be the more efficient the more radically they differ from the point of view to be investigated" (1965a, p.214, italics added). Nothing is more radically different than incommensurable cosmologies, starting from their lack of synonymy which, by itself could increase the chances or even be a "sign of success rather than of failure" (1965a, pp.185-202).

It is well known that in philosophy, the term 'divergence', owes a great debt to Mill's proliferation and his four grounds for adopting it (Mill, 1961). So, proliferation is not a new idea. Besides that, proliferation has had broad connections with the notion of struggle between alternatives since the pre-Socratics (1981 [1970]). In modern scientific tradition, the source of the term 'divergence' provides a natural bridge between Feyerabend's notion of proliferation and the struggle of alternatives.

We are referring to the principle of divergence in Darwin's theory. Feyerabend emphasized that Darwin's theory influenced the idea of struggle of alternatives (1981 [1970], p.144). Feyerabend clearly made that connection in two occasions. First in in the paper "Outline of a pluralistic theory of knowledge and action" (1999 [1968]) where Feyerabend compared his proliferation with the Darwinian mechanism of natural selection (1999 [1968], p.106). Second, in the paper "Consolation for the Specialist" (1981 [1970]). In both cases, Feyerabend used the term struggle to underline one of the marks of his proliferation. Just like in Darwin's natural selection, where species evolution goes regardless the "existing species happen to be well adapted" (1999 [1968], p.106), theoretical proliferation must also go on despite the level of development of our mainstream theory.

It seems that Feyerabend's observation on this conceptual debt with Darwin lead him to extend such a Darwinian influence from 'proliferation of species and variations' upon the notion proliferation with divergency. Not rarely Feyerabend uses terms of natural selection, such as 'divergence' in proliferation of alternatives, extinction, mutations, struggle, unfitness, and ecological niches, in many texts. Examples ranges from Against Method (AM) (1975 1993), Conquest of Abundance (1999), "Problems of Empiricism" (1965a), "Problems of Empiricism - part2" (1970), "Consolation for the Specialist" (1970), to papers like "Two models of epistemic change: Mill and Hegel" (1981), just to mention some of them.

Following this, in "Two models of epistemic change: Mill and Hegel" (1981e), Feyerabend again alluded to an evolutionary analogy. He himself made clear that in the nineteenth-century, proliferation and critical analysis of it, ${ }^{12}$ were both "defended by evolutionary arguments" (1981e, p.71, fn.11). He did not stop there. In Against 
Method (1993) and Conquest of Abundance (1999), Feyerabend used evolutionary metaphors to refer to his principle of proliferation as a part of a Darwinian view of divergence and struggle for existence, explaining that some theories fit better than others.

On this account, let us take a look at Darwinian evolutionism. According to it, the mechanism of natural selection posits that, when the conditions are minimally favourable, species reproduce in large numbers so as to sustain their existence. This is as part of the so-called Darwin's populations account ${ }^{13}$ (Godfrey-Smith 2009), and how part of the mechanism of proliferation works too. But proliferation is not enough and that is why the principle of divergence comes out in Darwin (C. Darwin 2009 [1859]), and, as we will see, in Feyerabend. It fits well for both views.

Roughly speaking, in Darwin, species need to proliferate in a large number (as part of their survival strategy). However, this proliferation are more successful when followed by divergence in variations, to keep up with the challenges of natural selection. By this principle, the mechanism of natural selection acting upon the Malthusian principle of population, new species are born as product of a function of different features in action (F. Darwin \& Seward 1903, p.1:118). Add to this the fact that, due to natural selection, variations generate more different species. These variants on its turn gives origin to "different members of offsprings either in immediate and in remote generations (the principle of differential fitness)" (Godfrey-Smith, 2009, p.70).

That being said, continuous proliferation in a divergent fashion is part of the way life deals with the, as Darwin putted, polity of nature, according to Darwin's principle of divergence. The principle states that "the more diversified the descendants from any one species become in structure, constitution, and habits, by so much will they be better enabled to seize on many and widely diversified places in the polity of nature, and so be enabled to increase in numbers." (C. Darwin 2009 [1859], p.87).

Of course, increasing in numbers is not just a matter of quantity, but also of structure and species survival. Variation of traits is not only about individual characters, but also about the fitness of organisms. Moreover, nowadays we now the fitness is also a dynamic element, changing, and even diverging from its previous form (GodfreySmith, 2009). Thus, as stated in Darwin's principle of divergence, the branching of species into a great variety has as one of its outcomes a wide divergence of structural characteristics of the descendants. After all, Malthus called Darwin's attention to the fact that the struggle for existence, combined with population growth, has the potential to bring up species transmutations (C. Darwin 2009 [1859]; F. Darwin \& Seward 1903). The chances of a selective advantage of variant species in a very complex and diversified world is then increased (C. Darwin, 2009 [1859], p.89). That is how nature, if we see it as an entity (Richards \& Ruse 2016), has its own polity. Therefore, according to the polity of nature, the more divergent the growth of members of a population, the more the chances of diversified descendants, which will hopefully 
bring adaptive advantages. ${ }^{14}$

By this account, Darwin's principle of divergence offers to Feyerabend an interesting analogy on the necessity of divergence in his principle of proliferation-tenacity. This is why he promoted that analogy in many papers beyond "Outline of a pluralistic theory of knowledge and action" (1968), although with small adaptations. For instance, in 1970, Feyerabend kept the comparison between proliferation-tenacity and Darwinian principle of divergence. The difference is that, by this time, he referred to the interplay between proliferation and tenacity. He says in "Consolation for the Specialist" that such an interplay "may be the only possible means of preventing our species from stagnation." (1981 [1970], p.144), and his is not using species in a accidental sense, but in an appropriated biological and epistemological sense.

The interplay between proliferation and tenacity makes it clear that proliferation will not reign alone. Rather it needs to be critically checked by tenacity (1981 [1970], p.144). In the phrase, our species avoid to fall into dogmatism of any kind as a result of this interplay. So, from an epistemological viewpoint, Feyerabend is interested in the advancement of knowledge, though he was more concerned with sustaining the movement of the research so as to avoid the petrification of ourselves, as a species. ${ }^{15}$

Thus, developing the interplay between the principles of proliferation and tenacity, Feyerabend claims that knowledge "can be advanced by a struggle of alternative views" (1981 [1970], p.144, italics added). That is, advanced in the sense of pushing forward the development of new answers, which can thrive or decay when facing other theories on that struggle (1993, pp.269-70; 1999, pp.215, 240). Likewise, the interplay between new accounts (species), and a critical retainment and competition played by them - which are also marks of tenacity (struggle and critical comparison) - allows us to associate potential advances with proliferation and competition, similar to Darwinism (1981 [1970], p.144).

Hence, Feyerabend helps us to see that proliferation, associated with divergent and competitive features, can benefit the progress of knowledge as much as these elements benefit organic evolution, preventing species from stagnation. Dogmatism is as bad for knowledge as it is for evolution.

To conclude this point, it is worthwhile to recall that Feyerabend explicitly says that the "interplay between proliferation and tenacity also amounts to the continuation, on a new level, of the biological development of the species" (Feyerabend 1981 [1970], p.144). Clearly, then, Darwin's influence went beyond the relation of proliferation from Darwin's evolutionary theory. Feyerabend reflected on something present in the mechanism of natural selection, the so-called Darwinian Principle of Divergence, ${ }^{16}$ and how it provides a precious resource for the diversity of responses, including on a cosmological level.

Feyerabend saw the proliferation of universal theories and their struggle for existence as a necessity for progress. Not only because proliferation is a good source 
of criticism of the mainstream position, which can create "patterned resistances to widely divergent point of views" (1993, p.165), but also because it motivates a less constrained life with theoretical freedom for individuals to develop their preferred forms of life and realities. This is why Feyerabend observed that science needs inventive people, so they could develop alternatives that defy our perception, language, thoughts, experience, theories and 'reality'. That is, science needs people who can explore divergent cosmologies even when the plurality of cosmologies does not entail guaranteed improvement of our knowledge (1981 [1970], p.138).

Therefore, proliferation of cosmological alternatives concerning the development of knowledge and individual consciousness needs to be taken not as "a series of selfconsistent theories that converges towards an ideal view" (1965b, p.107; 1993, p.21, italics added) or a single stage of progress concerning "a preliminary stage of knowledge which will at some time in the future be replaced by the Only True Theory" (1999 [1963], p.80).

On the contrary, divergent cosmological proliferations do not converge towards 'Truth', where the scientific view projects "one response onto it[Nature] as describing its true shape", but rests on a blueprint that encourages "an ever-increasing ocean of mutually incompatible alternatives" (1993, p.21, bracket added). ${ }^{17}$ Necessarily, but not sufficiently, these alternatives produce good results when they seek fundamental disagreements, feeding pluralism about and in science that contests facts in an incommensurable fashion (1999, p.239). That is, the plurality "inherent in science itself" allows the scientist to search for responses from Nature by "adopting different myths and using corresponding procedures", and, despite the fact that the adoption of plurality may create incommensurable views, many of them cosmologically divergent, such mythical differences and procedures still manage to "get respectable results" (1999, p.239). And why is that the case? Because incompatible cosmological alternatives, regardless of the limits of the materials that scientists work with (1993, p 269), reveal that when "being approached in different ways Nature gives different responses" (1999, p.239). This reveals that the world, or Being, "responds differently, and positively, to many different approaches" (1993, p.270). Cosmological divergent proliferation can give us not only results, but respectable results.

To illustrate this, let us settle one example in history of science which is not found in Feyerabend's examples. The case concerns the evolutionary debate in the 19th century. Darwin, who was an antievolutionist at first (at least until early 1837), due in part to his commitment to Lyell's antievolutionary worldview (linked to his nonprogressive world picture about the origin of organic beings), changed to an evolutionary approach around early 1837 , at least to a saltatory form of evolutionism when the "ornithologist John Gould convinced Darwin that the finches formed real species, not just varieties" (Ruse 1999, p.166). From that moment on, Darwin not only switched theories, but cosmologies and proposed a new reality that had deep influence on 
basically every scientific field, and on non-scientific fields as well. Darwin's theory then touched everything that there is, within and outside science. He went from an essentialist philosophy that usually supported an antievolutionist view based on "a static world picture" (Ruse 1999, p.5) to a non-essentialist and progressionist view. This view supported a kind of law-bound world explained by an evolutionary theory, and in that world even the entities proposed (like finches) were not varieties of the same species, but rather were completely different species.

At this point the reader may wonder how this case is an example of proliferation. Well, first, Darwin changed his view more or less around the spring of 1837 (Ruse 1999, p.160). However, at that time, this did not mean that all other theories, antievolutionists and evolutionists, were automatically rejected. On the contrary, different versions of evolutionism, such as the teleological version of Lamarck or Asa Gray's view of evolutionism, and also antievolutionism, such as Cuvier's teleological view or Owen's archetypal, were competing side by side with Darwin's evolutionism. This is interesting because Darwin's theory was not completely accepted even after the release of The Origin of Species (C. Darwin 2009 [1859]). Unsurprisingly, each of these views had their own ontological divergence resulting in different realities, and different realities entailing deep consequences for everything that there is. Even "Darwin himself recognized, his thinking was always more than just about scientific explanations of the organisms occupying the physical world. His thinking pointed the way to a new or revived philosophical perspective on reality." (Richards \& Ruse 2016, p.1, italics added). Darwin's evolutionary theory posits a new theory of the organic and inorganic world, new entities (theoretical and phenomenological), new logical relationships between these entities, new practices, and moral and religious implications for science and our daily lives, and above all this, new world.

In this account of pluralism, the more divergently we can proliferate, sometimes, the better it can be, and this is the case despite the fact the pluralism is not a general logical necessity for progress. For our purposes, it is noteworthy to say that divergent theories sometimes can be translated into incommensurable and universal theories which can result in a complete change of cosmology (1993, p.165; 1999, p.239). We said 'sometimes' because Feyerabend acknowledges that not all alternatives are suited for criticism (1965b, p.109), and not all alternatives are widely divergent enough and inconsistent enough to bother the status quo and to be seen as incommensurable alternatives to our comprehensive view of the world (1993, p.165). On the other hand, divergence is itself not rare, and it may even "proliferate" across scientific disciplines such as psychology, medicine, biology, and physics (1987, p.75). However, once again, it does not mean that such proliferation will always produce incommensurable theories. Nor does it mean that a change in our cosmology entails improvements to our scientific knowledge. Pluralism does not provide epistemological guarantees (Feyerabend 1981 [1970], p.138). 
Thus, the divergent proliferation of incommensurable theories in Feyerabend is not primarily a matter of theoretical proliferation but rather of cosmological proliferation. Cosmological proliferation, he says, is not only incompatible with unitarian realism, but it also assumes that knowledge cannot be reduced to a basic theory or discipline, like physics, and also that "Being, or Basic Reality reacts in a positive way" to a multitude of approaches even from a factual perspective (Feyerabend 1999 [1994], p.215). ${ }^{18}$ As he pointed out, since our world is a "largely unknown entity", it would be senseless to "restrict ourselves in advance" in the task of discovering "not just a few isolated 'facts', but also some deep-lying secrets of nature" (1993, p.12). ${ }^{19}$ Moreover, since our world is a largely unknown entity to be explored, and we are limited beings trying to cover a complex and abundant world, it seems reasonable to proceed with a cosmological proliferation of theories.

But to start with, we must first take a step back from the cosmology that stands in the centre of attention. This action resembles a form of skepticism about the status quo worldview (Paul Feyerabend 1970, p.301; 1993, p.117). Feyerabend then says that "the first step on the way to a new cosmology is" - and by the first step he meant to create a safe environment of competition for the multiplication of new incompatible alternative cosmologies - "we have said, a step back" from the status quo. (1970, p.301; 1993, pp.113-17). In other words, Feyerabend encourages an intellectual modesty in a practical fashion that helps us keep "away from the tyranny of tightly knit, highly corroborated, and gracelessly presented theoretical systems" (1993, p.117). This skeptical attitude, as a part of proliferation, is especially important when the status quo creates a pattern of resistance to widely divergent views. Consequently, what Feyerabend called a step back "is, as a matter of fact, a step forward" (1970, p.301; 1993, p.117) because by proliferating cosmologies and putting all of them under critical examination, it contributes to the development of our collective knowledge, individual mental faculties, and liberation.

Therefore, on the one hand, the need for proliferation of cosmology is associated with our limitations and the abundance of the world, as a largely unknown entity. On the other hand, from a strategic viewpoint, this need starts with some skepticism, ${ }^{20}$ by taking a step back from what we already know, established for us by the paradigm cosmology.

To sum up, our interpretation of Feyerabend's principle of proliferation, first, the principle is concerned, though not restricted to, the introduction of alternatives (upper and lower-level kinds) with divergent natures, where each will force the others, by competition, to enhance its critical powers (1993, p.25), but respect concrete cases $^{21}$ (1981e, p.71, fn 11). Darwin's principle of divergence, which assumes that the divergence in species [alternative views] increases their opportunities "to seize on many and widely diversified places [concrete cases] in the polity of nature [complex world]" (C. Darwin 2009 [1859], p.87, brackets added). This has influence on Feyer- 
abend's divergence principle. Secondly, those alternatives contribute when diverge in ontological and incommensurable fashion (Paul Feyerabend 1965b, p. 105). So the most epistemically profitable, although not exclusively, so divergencies are inclined to proliferate cosmological views. Third, non-elimination of older and refuted theories (setback and tenacity retainments), while encouraging their enhancement and mutual criticism by comparison, is only possible by the interplay, or active interaction, between proliferation and tenacity. This is due in part to the consequences of that skeptical view of knowledge, and also to the epistemic values that every view is born with, since somehow they can still "contribute to the content of their victorious rivals" (1993, p.34; 1965, p.224). This point can also be approached from the other way around, that is, the active interaction can also keep alive the possibility of a triumphant return of the defeated theories, i.e., theories that ran out of steam. It is here that proliferation shares an exciting blurred border with tenacity.

Let us now consider all that we have explained as the constructive features of proliferation. Feyerabend said that he thinks proliferation is an "an essential part" of scientific progress and that "knowledge needs a plurality of ideas" (1993, p.131). Nevertheless, is the principle of proliferation-tenacity a strict necessity? This depends on what we meant by strict necessity. In a logical sense, there is no necessity. But if we mean necessary as a practical enrichment of a pluralistic cosmology and humanitarian approach, then it is.

In a famous part of Against Method, when Feyerabend is arguing about an intrinsic connection between theories and facts, he says that the methodological reason to adopt proliferation is that "there also exist facts which cannot be unearthed except with the help of alternatives" (1993, p.27, italics added). The first thing to be noticed here is that when Feyerabend says that "there also exist facts", we interpret the adverb also as pointing out that there exist facts that do need alternatives in order to be unearthed, as well as others that do not. Regardless, it does not dismiss proliferation as a non-logical necessity.

Thus, the logical necessity does not apply to all cases; sometimes knowledge progresses without proliferation. Feyerabend reminds us that 'no material harm' will come from the suppression of alternatives, therefore science can exist without pluralism (Paul Feyerabend 1981e). On the other hand, "there are circumstances, not factually circumscribed or determined in any other way, in which we must introduce ideas that contradict them [the irrefutable laws of thought]" (1981e, p.71, fn 11, italics and brackets added). That is, there are circumstances where pluralistic divergence is necessary for the development of new solutions, and for the test of theories because it can help us strengthen them (1999 [1968], p.110). Proliferation helps us perceive that "knowledge is obtained from a multiplicity of views rather than from the determined application of a preferred ideology" (1993, p.37).

Thus, strictly speaking, proliferation is not a matter of logical necessity. As Bschir 
(2015) noted, if it was a matter of mere logical necessity, then just one case in the history of science where scientific progress was made or where facts were unearthed or theories changed without proliferation would be enough to reject such view of proliferation as necessary. In fact, what Feyerabend is saying is that proliferation is not a matter of some strict rule or logical necessity for progress. Not even Popper believed in this strong claim for logical necessity (Popper 1959, part I). Rather, it is only a matter of finding ways to enrich our limited views on an abundant world, avoiding restriction of our individual freedoms. Proliferation is a form of presenting solutions of problems whereas attempting to growth our consciousness about some tyrannical view that could, we never know, ending up being wrong (Feyerabend 1981e, p.67).

Using a spiritual and straightforward metaphor about the proliferation of our alternatives, Feyerabend replies to Wolff's criticism of Mill's pluralism by exploring the advantages (not the logical necessity) of having options:

Of course, 'no material harm' (16) will come from the suppression of history and of alternatives just as brothels do not suffer from the philosophical ignorance of the whores; they flourish, and continue flourishing. But a philosophical courtesan certainly is preferable to a common broad because of the added techniques she can develop; and a science with alternatives is preferable to the orthodoxy of today for exactly the same reasons. (1981e, p.71, fn.10).

What we have argued about Feyerabend also reflects our position concerning the fundamental aspects of proliferation-tenacity. That is, we cannot approach him primarily from a methodological or epistemological viewpoint. To fully understand Feyerabend's proliferation, one should see his philosophy from a cosmological viewpoint, and then observe how it is related to methods, theories, facts and their relations.

Proliferation does not entail that all criticisms resulted from an ocean of anomalies upon every theory will necessarily create progress, neither that pluralism is the only way. Science can flourish without proliferation. To think otherwise would be not only a philosophical mistake but also a misunderstanding that would turn proliferation into a restricted recipe. From the very beginning of Against Method, we were told not to do this because "there are no general solutions" (1993, p.xiii) to science questions. Feyerabend does not argue for such an idealistic or naive anarchism by taking proliferation out of the concrete cases, goals, or contexts it touches (1993). Proliferation is not "proposed as a solution to epistemological problems such as Hume's problem, or the problem of the testability of general statements" but rather as a path to develop our consciousness, freedom, autonomy, and human growth (1981e, p.67). Proliferation is used to enrich all forms of life, while enabling us to learn from them (1981a, p.31; 1981e, p.67). It is a cosmological element that helps us with the conquest of the abundance of the world. 
Proliferation of alternatives also brings fresh air to criticism, i.e., "criticism is facilitated by proliferation" (Paul Feyerabend 1981d, p.vii). This argument of facilitation of criticism could bring the most surprising results, especially when it is openminded to new criticisms, coupled with pluralism. Any fairytale (theory, conjecture, myth) that "tries to develop our ideas and that uses rational means for the elimination of even the most fundamental conjectures must use a principle of tenacity together with a principle of proliferation." (Feyerabend 1981 [1970], p.143, italics added). The reason for this recommendation is simple: divergent pluralism can enhance our criticism towards of accepted theories and unquestionable facts by questioning what seems to be the most fundamental conjectures, those "as plain and straightforward as daylight itself." (1981 [1970], p.138).

To summarize, we have talked about proliferation and how it encourages us to divergently invent or revive theories from a cosmological point of view as well. Some of the main aspects of the approach, in respect to concrete cases, are the continuous introduction of theories, competitiveness of theories with critical strengths (struggle for existence). The introduction of theories, clearly needs this critical dimension, which lead us to talk about tenacity, from a cosmological viewpoint through the active interaction, and our observation of its practical suspension (step back), i.e., a recommendation to suspend our theories from the battlefield of competition until they are ready for fight again.

\section{Principle of Tenacity from a cosmological proliferation approach}

The complementary part of the principle of proliferation is the principle of tenacity. This principle, although not thoroughly analyzed by Feyerabend, ${ }^{22}$ is intimately related to proliferation, to a humanitarian outlook, and to the progress of knowledge (1999 [1968], p.111). The humanitarian view, when intermediated by the active interplay of principles, does not need to sacrifice individual liberation and the development of mental faculties as collateral damage to reach scientific progress. The intimacy between tenacity and proliferation motivates tenacity's retainment of theories for further development and never for the elimination of new or old ones.

Nonetheless, the following questions emerge. Why should retain and further develop theories? How did Feyerabend defined tenacity, and how did it change from the 1970s onwards? Tenacity was first defined in the paper "Outline of a pluralistic theory of knowledge and action" (1999 [1968]) and then in "Consolations for the Specialist" (1981 [1970]). In "Outline of a pluralistic theory of knowledge and action" (1999 [1968]), besides the interplay of tenacity and proliferation, Feyerabend defines tenacity based on three elements. They are 1-attractiveness and 1.1- promises 
of fruitfulness; and 2- retainment of theories. They are mentioned as follows, "first, that we select from a number of theories the one that has the most attractive features and that promises to lead to the most fruitful results; and second, that we stick to this theory despite considerable difficulties"23 (1999 [1968], p.107, italic added). It is crucial to note here, as Shaw (2017) reminds us, that we cannot be sure if these items should be taken in Popperian fashion or Feyerabendian fashion. Second, the enumeration of these items has a subcategory for methodological reasons, as Feyerabend explained in the quotation. That is why we classify these three items in two larger groups operating on criticism guidelines. Hence, items 1-attractiveness and 1.1-promises of fruitfulness are part of just one group in respect of the tenaciously pluralistic model of theory selection, whereas 2- the retainment of theories, is the second part of tenacity, what we call setback for improvement of theories.

Two years after "Outline of a pluralistic theory of knowledge and action" (1968), with the publication of "Consolations for the Specialist", Feyerabend outlined tenacity almost with the same words as he did in 1968, maintaining fruitfulness and retainment, as constitutional items. The difference was that he did not specify attractiveness, as he did in 1968. In the paper "Consolations for the Specialist" Feyerabend describes tenacity as "the advice to select from a number of theories the one that promises to lead to the most fruitful results, and to stick to this one theory even if the actual difficulties it encounters are considerable" (1981 [1970], p.137, italics added). On both occasions tenacity retains the pluralistic selectiveness from many theories, but in "Consolations for the Specialist" tenacity is based just on 1.1-promises of fruitfulness, and 2-retainment of theories, without mentioning item 1-attractiveness.

These items undoubtedly pulls Feyerabend away from many forms of relativism, especially the radical ones. Nevertheless, it does not answer why attractiveness disappeared, and what fruitfulness and retainment mean. Feyerabend was aware of the problem that to explain tenacity he needed to approach it from a methodological perspective (1981 [1970], p.137). From this view point, he justifies items 1.1-promises of fruitfulness, and 2-retainment of theories with a single argument. Before we explore the disappearance of item 1, let us first check the argument for item 1.1 and 2.

With regards to item 2-retainment, he supports it with the need for a critical development and improvement of theories (1981 [1970], pp.137; 143-44). Moreover, about 1.1-promises of fruitfulness, he says that theories, if retained (item 2), "may eventually be able to accommodate the very same difficulties" that earlier they were not (1981 [1970], p.137), including difficulties from experimental and factual approaches. In few words, we retain theories because of their unguaranteed promises of fruitfulness, such as accommodation of difficulties.

On the next page of the same paper, Feyerabend repeated that we should retain our theories regardless of recalcitrant facts, especially those supported by the mainstream theory. He says that theories are hardly compared to facts and evidence, and 
that our plain facts are pervaded by the accepted theories, granting "no guarantee that a fundamental change in our cosmology, such as a change from a geostatic to a heliostatic point of view" would bring any improvement (1981 [1970], p.138). This is the reason Feyerabend goes on and says that fruitfulness could lead to improvement by suspending the effects of T upon T', T". We must, for methodological purposes, suspend the repercussions of our mainstream theory $\mathrm{T}$ over the possibilities of how to do a research about a concrete subject matter, so we can proliferate other theories, T', $\mathrm{T}$ ", $\mathrm{T}$ " "which accentuate the difficulties of $\mathrm{T}$ while at the same time promising means for their solution." (1981 [1970], p.138, highlight added). Again, the promise of a solution is nothing but the unguaranteed promise of fruitfulness.

That being said, Feyerabend corroborates the promises of fruitfulness by interplaying it with proliferation. He says that, on the one hand, proliferation recommends that everyone "may follow his inclinations", because science, "conceived as a critical enterprise", benefits from it (1981 [1970], p.143). However, he also says that tenacity encourages us not "just to follow one's inclination, but to develop them further, to raise them, with the help of criticism (which involves a comparison with the existing alternatives) to a higher level of articulation and thereby to raise their defence to a higher level of consciousness" (1981 [1970], pp.143-44, highlights added). Considering that Feyerabend is not stating a general rule but advising us to look at these principles in concrete cases, then only something that promises development and articulation is fruitful and can be kept in the competition. He further says that the interplay between proliferation and tenacity "may be the only possible means of preventing our species from stagnation." (1981 [1970], p.144). That is, to keep knowledge progressing, instead of only retaining theories, or inventing them, with the sole purpose of proliferate, we should also continue to look for fruitfulness. So as we argued, all these arguments demonstrate that items 1.1 and 2 remain part of tenacity, even after 1968.

What about attractiveness? The first thing to note is that attractiveness is not worked out in "Consolations for the Specialist" (1970) or anywhere else, at least, not the way fruitfulness and retainment were. At the most, in the paper "Consolations for the Specialist" Feyerabend mentions some ideas that suggest he is talking about attractiveness (1981 [1970], p.146). He repeat some of these suggestions on other occasions, as in Against Method. For instance, he suggests that to start a new trend that radically disagrees with the current view, that is, performing what we call divergent proliferation, it is sufficient to have plausibility and perhaps some factual support (1970; 1981 [1970], p.146; 1993). To him, although a cosmology only needs to have features that "seem attractive to some people" (1970, p.301; 1993, p.117), there is always "some partial support and partial plausibility" that suffice to "become the starting point of concentrated effort", that is, attractive enough to start a new trend, cosmology (1970, p.301; 1993, p.117). In other words, plausibility and some factual 
support are attractive features, at least to start a new trend, a new cosmology that represents a step back from old, evidence, old trend, old cosmology.

Feyerabend says that all theories are born with some empirical or abstract support (neither very, not zero) (1970, p.301; 1981 [1970]; 1993, p.117), and since all theories have some form of these attractive features, then any empirical support found either in the status quo or in its alternatives, give no reason to keep us confined to a monistic view. On the contrary, proliferation and tenacity encourage even "a step back from the evidence" in order to proliferate new cosmologies from a plausible abstract or empirical support (1970, p.301; 1981 [1970], p.142; 1993, p.117).

From the attractiveness viewpoint, there is no option but assuming that the fundamental difference between the status quo and its alternatives is an idiosyncratic theoretical incommensurability through "features which at the time in question seem attractive to some people" (1970, p.301; 1981 [1970], p.142, italic added; 1993, p.117). Naturally, the same features could not be attractive to other cosmological view. Therefore, the very notion of attractiveness changes with the criteria, time, theoretical relationships, evidence, and each cosmology. After all, it is highly unlikely that evolutionary and antievolutionary theories share the same notion of attractiveness. They will also not share fruitfulness. This is why there would be no sense in making a list with items that would be attractive in all contexts, cases, and time.

Notwithstanding, how the progress of knowledge is helped by these specific features of attractiveness since, ultimately speaking, Feyerabend is arguing for cosmologically incommensurable idiosyncrasies? One reason is that Feyerabend's idiosyncratic argument must not be seen in the same sense is generally the word idiosyncrasy suggest. Usually, this word suggest a view that only exists to please the individual who propose it, being unattainable and detached from the problem at hand, and from other individuals. With respect to scientific knowledge, Feyerabend's idiosyncratic view balances the traditional sense of offering an individual perspective, a new cosmology, with the necessity of contrasting its attractiveness with other individuals alternatives in a competition, from a specific goal and context.

This balances contributes to explains why is a mistake to consider Feyerabend's anything goes a philosophically relativistic rule, instead of the practical observation of scientific research, debate, and procedures. Only under generally monistic and rationalistic terms would there be an effort to find a principle that fits in all circumstances (Feyerabend 1993, p.19). Feyerabend reminds us in the preface of Against Method that "anything goes" is not a principle because "I do not think that 'principles' can be used and fruitfully discussed outside the concrete research situation they are supposed to affect" (1993, p.vii, italics added). In other words, Feyerabend does posit criteria for theory evaluation and comparison. What he does not want to is assume that science has universal, uniform, and atemporal criteria for that.

Therefore, ultimately, all features of tenacity face competition and evaluation 
in a critical way. Moreover, our interpretation about the meaning of competition in Feyerabend is that it is of two types.

The first is what we call the internal competition, when the elements of a theory compete internally for space in concrete cases. This view, which is a consequence of Feyerabend's conception of competition in tenacity, assumes that since no theory is entirely developed, every theory searches for self-improvement. To do this, every theory tests different internal elements, conditions, and exchanges with auxiliary sciences (all of which are undergoing the same process).

Second, we call this meaning the external competition. It happens when one theory forces others into greater articulation, in some concrete circumstance inside the same area of knowledge, or respect to a problem, or a goal. This brings different results, which are attached to specific contexts and interests, leading to the fact that "not all approaches to 'reality' are successful" (1999, p.215).

Thus, since all theories are already attractive and fruitful because every theory seems to be "attractive to some people" (1993, p.117, italic added) and born with some form of support, then there is in all theories an inherent promise to be fruitful and attractive. The origin of this inheritance is that, soon or later, every theory will face the inevitable competition. From all this, we are able conclude three things.

First, all theories are attractive and fruitful because they are born this way, at least to some extent, and to their own supporters. Interestingly, even propaganda could become an attractive feature. Feyerabend argues that this is how part of "Galileo's work should be seen" [1993, p.118]). When natural interpretations covert by the status quo make impossible to consider new cosmologies, propagandas can give a nice contribution to the progress of research. Second, attractiveness and fruitfulness depend on theoretically internal and external competition. Under concrete circumstance, each cosmological theory has different levels of development; that is why they need tenacity. Third, since no theory and idea is "completely without abstract or empirical support" (1970, p.301; 1993, p.117), which makes it attractive, then, as a result, every theory must always be retained due to the possibility to evolve.

However, Feyerabend did not hold that such partial support and achievement (any theory that "has been around for some time has achievements" (1993, p.30)) testifies that all theories are born with the same support. Neither it does say that they would reach the same achievements. Otherwise, it would make no sense to assert that theories can evolve, much less in a pluralist fashion. In other words, theories have quantitatively and qualitatively different values from the attractive and fruitful viewpoint, values that may change as time passes by and the struggle for existence acts.

As a consequence, Feyerabend claimed that some theories will succeed, at least temporarily (1993, p.270 1999, p.215), instead of all theories (something closer to what a relativist would say), or not a single theory will (as a skeptic would say), or 
just one will succeed (as a uniformist/unitarian would say). Theories will succeed through the struggle for existence, but also not every theory in the competition will prove to be equally attractive and fruitful. Neither will a single theory prove to be the One True Champion, for there is hardly any support that fits flawlessly to all concrete cases.

Divergent proliferation and tenacity pursue alternative theories in concrete cases, and not to make all of them accepted, but instead to make some of them minimally acceptable ${ }^{24}$ that is, able to be a part of the competition and perhaps accepted in the future. We must embrace our own inclinations, since "it is advisable to let one's inclinations go against reason in any circumstances" (1993, p.116). However, if we do this, what guarantees that a divergence of cosmologies is epistemologically progressive? There is no guarantee that alternative views tenaciously treated will succeed (1981 [1970], p.138). We are limited beings within a complex world where, until now, only "the Good Lord, who stands above all laws of nature and is not bound by them, is able to point out" (1999 [1968], p.108) to any kind of guarantee. The best we limited mortals can do is not restrict ourselves in advance, especially if divergent cosmological views, criticisms, theories and methods are coming from "outside the range of the routine responses" (1993, p.169). This approach helps science to sustain the movement of the whole and the richness of research, which is ethically and epistemically more concerned with the real scientific practice than some abstractive suggestions. ${ }^{25}$

Returning to the issue of competition, we observe that a theory is usually temporarily adopted "because it seems to be attractive for some reason or other." (1965a, p.238, italics added). Such attractiveness has cosmological dependence, given that "[e]xperience is reinterpreted in order to be 'close' to this theory [claiming attractiveness], and the theory is then defended by empirical argument, by pointing out how closely it fits the facts." (1965a, p.238, Brackets added). Notwithstanding, it turns out that attractive qualities of one theory, such as fit with the evidence, have no independent value, and that is why they must not only be contrasted with other views, but also looked at within concrete cases.

The maximization of empirical data by itself would not be an attractive feature of all theories. On numerous occasions, Feyerabend is clear about the idea that scientific theories "to give an example from our own civilization, branch out in different directions, use different (and occasionally 'incommensurable') concepts and evaluate events in different ways" (1987, p.75, italics added). That being so, if one is waiting for a list of universal features of what is attractive and fruitful, we will not offer that list.

Furthermore, even if such a list were provided, it would not be of any help in the competition of concrete research, for the specificities and interests that each scientific episode requires and the restrictive nature that such a list and rules impose, would 
render that list pointless. With relation to this, Feyerabend asks us:

Will he [a scientist] follow the barren and illiterate logician who preaches to him about the virtues of clarity, consistency, experimental support (or experimental falsification), tightness of argument, 'honesty', and so on, or will he imitate his predecessors in his own field who advanced by breaking most of the rules logicians want to lay on him? Will he rely on abstract injunctions or on the results of a study of concrete episodes? I think the answer is clear [...]. (1993, p.197).

As we have shown, the solution of problems is now taken after each concrete case, not before it, that, scientists "are like architects who build buildings of different sizes and different shapes and who can be judged only after the event, i.e., only after they have finished their structure. It may stand up, it may fall down - nobody knows" (1993, p.2, italics added). We do not know beforehand which theory is better, and the merely contradiction between theories and new ones is not enough to show "which view is the better one" (1993, p.113). Rather, the mere contradiction only shows which one is more familiar, that is, a "straightforward and unqualified judgement of theories by 'facts' is bound to eliminate ideas simply because they do not fit into the framework of some older cosmology." (1993, p.52).

Knowledge is not the result of convergency or consistency. It is instead a process of divergence and competition, a contrasting process, "an ever increasing ocean of mutually incompatible alternatives" (1993, p.21) that work collectively to promote individual improvement where every view is "part of the collection forcing the others into greater articulation" (1993, p.21).

What this paper has thus far striven to show is that this whole process of idiosyncrasies is not a defence of philosophical relativism, but of pluralist freedom. Theories are still evaluated and may fail in Feyerabend's view but not outside the situation they affect.

What happens with the theories that do not succeed? Are they definitely deleted and eliminated from our knowledge? We argue that Feyerabend (1961) does not think so, especially because in 1961, when he discusses Grunbaum's conventionalism, he states that it is in principle impossible for a theory to be entirely eliminated due to confirmation holism. Rather, theories that are defeated are seen as simply running out of steam. Perhaps, they could triumphantly return to the main table and accommodate previous difficulties. Such has happened more than once. Since there is no way to know when or if it will happen again, then theories "may have to be retained forever" (Feyerabend 1993, p.157), even if it means that they will not necessarily be used. This lead us to our final topic: tenacity's practical suspension. 


\subsection{On Practical Suspension (Setback - theories that temporarily ran out of steam)}

We call the next aspect of our proposal the Practical Suspension or Practical Setback in Feyerabend's pluralism (1981b, p.140; 1999 [1980], p.214). The basic idea of practical setback is that defeated theories should be retained because they may simply "have temporarily run out of steam" (1981b, p.139; 1999 [1980], p.213). Defeated theories are retained to sustain vigour in the struggle for existence and to help with emerging difficulties. Sometimes the only way to reveal unfitness of a theory is not by analysis, as suggested by Bacon's method (Bacon 2003 [1620], aphorism 115), but by critical comparison. Since theories need time to develop, instead of being terminated and "rejected before they can show their strength" (1981b, p.139), then we should give them that time, give them space for a setback. However, "a setback for a theory, a point of view, an ideology must not be taken as a reason for eliminating it" (1999 [1980], p.214). Feyerabend advises that we need to proliferate because we do not have any divine omniscient eye in this complex world, so our only option, as limited beings, is to proliferate, or save the products of proliferation from elimination.

That being so, what happens with the defeated theories? Are they thrown away in the trash bin (terminated/eliminated), or are they just suspended from the competition until they are ready again? Feyerabend argues that theories can be suspended, and by the interplay of proliferation and tenacity, they might be enhanced and brought back in to the competition. In his view, there is no definite elimination of theories. ${ }^{26}$ We can evaluate theories and then reject them, i.e., consider them temporary setbacks, but in no way can we eliminate any of them. Cases in the history of science, such as Galileo's case, evolutionary's theory, and atomism, have shown us that the "lesson to be drawn from his historical sketch is that a temporary setback for a theory, a point of view, an ideology must not be taken as a reason for eliminating it" (1981b, p.140, italics added). Actually, if anything, elimination of theories eventually put us on the road to a monistic approach. If science is interested in progress, or generally putted, to find the truth, then it "must retain all ideas of mankind for possible use" (1981b, p.140). To do otherwise could undermine the progress of knowledge and humanitarian science, for "'[o]utmoded' views are kept alive both because they please some people and because the most advanced theories cannot be understood and examined without their help" (1999 [1980], p.214), that is, such an understanding asks a critical comparison.

The invention of theories by proliferation and the tenacious development and retainment of these theories does not mean mere accumulation, or simultaneous use of all theories. Occasionally, some proliferated theories are defeated. When that happens, a setback takes place, and the defeated theory get holds in a temporary suspension, a kind of recess from the process of competition to recover its strength. This 
suspension results and retainment may last forever, or not, it is uncertain.

The setback of theories is not Feyerabend's suggestion to leave theories out of competition because they are running out of steam. Instead, defeated theories require a temporary practical suspension, not elimination in traditional sense. To eliminate them would be like assuming infallibility. Second, after suspension, comes retainment. Third, retainment means that despite a theory being rejected, it might still be useful in many ways. About this potential usefulness, remember that Feyerabend states on two occasions that we "must retain all the ideas of mankind for possible use" (1981b, p.140; 1999 [1980], p.214). Every idea has some abstract or empirical support, after birth, and even after suspension. On this account, retainment of a defeated theory is a tenacious action that may helps with the progress of knowledge.

Furthermore, defeated theories can return because they can always profit from divergent proliferation, and not just because anyone is able to pursue his/her inclinations, in any circumstance, but rather because unexpected answers might only be disclosed with the help of retainment.

The interplay between proliferation and tenacity works so well not only because pluralism does not conceive knowledge as a product of a series of theories converging but rather because keeping in movement the process which cosmologies and their theories are temporary makeshifts. Under this view of nonconvergent theories, a scientist who wants to understand his views as clearly as possible "must therefore introduce other views" (1993, p.21). Thus, he must "compare ideas with other ideas... and must try to improve rather than discard the views that have failed in the competition" (1993, p.21). That being said, a scientist must not only compare and invent ideas, s/he must also retain them, for instance, "he will retain the theories of man and cosmos that are found in Genesis, or in the Pimander, he will elaborate them and use them to measure the success of evolution and other 'modern' views" (1993, p.21)

For clarity's sake, let us offer a brief example of this process of temporary suspension. The methodological attitude of practical setback could be metaphorically compared with a library where all of our theories (defeated or not) are books. In this case, our accepted and acceptable theories are the books on our desks, while the undiscovered, defeated and suspended ones are books on the shelves. It is normal and desirable that, once in a while, we check the books on the shelves, searching for new ideas, justifications, cosmologies, arguments, theories, insights, and answers which the books on our desk seem unable to provide. Maybe the answer is in the books on our desk, and we need a help from outside them to see it.

In this example, the books on the shelves are available for any possible use, because whatever worldview they hold, there would always be some form of abstract or empirical support in them. Moreover, it is also desirable that we keep buying more books, so that the library can continues to grow. It is also important to keep visit- 
ing and looking the books, reading or rereading them, comparing and using them to sustain the movement of critical competition alive. Roughly speaking, the process of development and evaluation of knowledge is, in general, an ever-increasing library whose owner neither burn nor ignores the books just because they hold defeated theories. Rather, the owner builds more shelves, buys more books, works through all of them, according to the problem and goals at hand in the moment.

\section{Conclusion}

When one divergently proliferates and tenaciously works, findinf new arguments or new facts (1993). Sometimes with their help, one develops new cosmological alternatives that enrich our knowledge and imagination and which open roads to the development of our mental faculties and conquest of abundance. For example, alternatives that "clashes with the most carefully established observational results and confounds the most plausible theoretical principles" are welcome (1993, p.22). Cases like this are common in history of science, such as the "Copernican view at the time of Galileo [which] was inconsistent with facts so plain and obvious that Galileo had to call it 'surely false'." (1993, p.39). As we have argued, divergent proliferation is not only a growth of theoretical alternatives, but primarily of cosmologies, whose pluralist nature brings up incommensurable disputes in the struggle for existence. In this account, the retainment of proliferated theories suggests that we must not eliminate defeated or untested theories. Otherwise, we would eliminate unique opportunities for the progress of knowledge.

So when Feyerabend recommends a practical setback of theories, and their retainment, he is proposing that, despite the suspension of cosmologies no longer accepted (or acceptable), these cosmologies could still become acceptable, and, if things go well for some of them, be accepted in the future. By taking advantage of this proliferation and tenacity, Feyerabend is trying to make his way into the abundance of the world, while remembering of our limitations, which is to certain extent flexible and unknown.

\section{References}

Athanasopoulos, C. 1994. Pyrrhonism and Paul Feyerabend: A study of ancient and modern scepticism. Hellenistic philosophy 2: 11-29.

Bacon, F. 2003 [1620]. The New Organon. L. Jardine \& M. Silverthorne (eds). 3rd ed. Cambridge, New York: Cambridge University Press.

Bailer-Jones, D. M. 2000. Modelling extended extragalactic radio sources. Studies In History and Philosophy of Science Part B: Studies In History and Philosophy of Modern Physics 31(1): 49-74. 
Benvenuto, S. 1995. Paul K. Feyerabend (1924-1994) - Search for Abundance. Telos 21(102): 107-114. doi: 10.3817/1295102107

Brown, M. J. 2016. The Abundant World: Paul Feyerabend's Metaphysics of Science. Studies in the History and Philosophy of Science Part A 57: 142-154.

Bschir, K. 2015. Feyerabend and Popper on theory proliferation and anomaly import: On the compatibility of theoretical pluralism and critical rationalism. HOPOS: The Journal of the International Society for the History of Philosophy of Science 5(1): 24-55.

Butts, R. E. 1966. Feyerabend and the pragmatic theory of observation. Philosophy of Science 33(4): 383-394.

Cartwright, N. 1999. The dappled world: A study of the boundaries of science. Cambridge: Cambridge University Press.

Chang, H. 2012. Is Water H2O? Evidence, Realism and Pluralism. Dordrecht The Netherlands; New York: Springer.

Chang, H. 2021. The coherence of Feyerabend's pluralist realism. In Interpreting Feyerabend: critical essays. Cambridge: Cambridge University Press, pp.40-56.

Darwin, C. 2009 [1859]. The Origin of Species - By Means of Natural Selection, or the Preservation of Favoured Races in the Struggle for Life. New York: Cambridge University Press.

Darwin, F., \& Seward, A. 1903. More Letters of Charles Darwin. London: Murray.

Farrell, R. P. 2003. Feyerabend and scientific values: tightrope-walking rationality. Dordrecht; Boston: Kluwer Academic Publishers.

Feyerabend, P. 1961. Comments on Grünbaum's "Law and Convention in Physical Theory". In: H. F. a. G. Maxwell (ed.), Current Issues in the Philosophy of Science. Symposia of Scientists and Philosophers. New York: Holt, Rinehart and Winston, pp.155-161

Feyerabend, P. 1962. Explanation, Reduction and Empiricism. Scientific Explanation, Space and Time. Minnesota Studies in the Philosophy of Science 3: 28-97.

Feyerabend, P. 1965a. Problems of empiricism. In R. Colodny (ed.), Beyond the edge of Certainty. University of Pittsburgh Press: Prentice-Hall, INC.

Feyerabend, P. 1965b. Reply to Criticism: Comments on Smart, Sellars and Putnam. Proceedings of the boston colloquium for the philosophy of science, pp.223-261.

Feyerabend, P. 1969. Science without experience. The Journal of Philosophy 66: 791-794.

Feyerabend, P. 1970. Problem of empiricism, part II. In R. G. Colodny (ed.), The nature and function of scientific Theories: Essays in contemporary science and philosophy (Vol. V4). Pittsburgh: University of Pittsburgh Press, pp.275-353)

Feyerabend, P. 1975. Against method: outline of an anarchistic theory of knowledge. London Atlantic Highlands, N. J.: Verso.

Feyerabend, P. 1981a. Historical background - Some observations on the decay of the philosophy of science. In: Philosophical Papers - Problems of Empiricism (Vol. 2) Cambridge; New York: Cambridge University Press, pp.1-33.

Feyerabend, P. 1981b. Introduction: Proliferation and realism as methodological principles. In Philosophical papers - Realism, Rationalism and Scientific Method (Vol. 1). Cambridge; New York: Cambridge University Press, pp.139-145.

Feyerabend, P. 1981c. Philosophical papers - Problems of Empiricism (Vol. 2). Cambridge; New York: Cambridge University Press.

Feyerabend, P. 1981d. Philosophical papers - Realism, Rationalism and Scientific Method. (Vol. 1). Cambridge ; New York: Cambridge University Press. 
Feyerabend, P. 1981e. Two models of epistemic change: Mill and Hegel. In Philosophical Papers - Problems of Empiricism (Vol. 2). Cambridge; New York: Cambridge University Press, pp.65-80.

Feyerabend, P. 1981 [1970]. Consolation for the specialist. In Philosophical Papers - Problems of Empiricism (Vol. 2). Cambridge; New York: Cambridge University Press, pp.131-161.

Feyerabend, P. 1987. Farewell to reason. London; New York: Verso.

Feyerabend, P. 1993. Against method. 3rd ed. New York: Verso.

Feyerabend, P. (1999 [1961]). Knowledge without foundation. In J. Preston (ed.), Philosophical Papers - Knowledge, science, and relativism (Vol. 3). Cambridge, New York: Cambridge University Press, pp.50-77.

Feyerabend, P. 1999 [1963]. How to be a Good Empiricist; A Plea for Tolerance in Matters Epistemological. In J. Preston (Ed.), Philosophical Papers - Knowledge, science, and relativism (Vol. 3). Cambridge, New York: Cambridge University Press, pp.78-103.

Feyerabend, P. 1999 [1968]. Outline of a pluralistic theory of knowledge and action. In J. Preston (ed.), Philosophical Papers - Knowledge, science, and relativism (Vol. 3). Cambridge, New York: Cambridge University Press, pp.104-111.

Feyerabend, P. 1999 [1980]. Democracy, Elitism and Scientific Method. In Philosophical Papers - Knowledge, science and Relativism (Vol. 3). Cambridge, New York: Cambridge University Press, pp.212-226.

Feyerabend, P. 1999 [1994]. Potentially Every Culture is All Cultures. In B. Terpstra (ed.), Conquest of Abundance - A tale of abstraction versus the richness of being. Chicago and London: The University of Chicago Press, pp.215-216.

Feyerabend, P., \& Oberheim, E. 2011. Tyranny of science. Cambridge: Polity Press.

Feyerabend, P., \& Preston, J. 1999. Philosophical Papers - Knowledge, science, and relativism (Vol. 3). Cambridge New York: Cambridge University Press.

Feyerabend, P., \& Terpstra, B. 1999. Conquest of abundance: a tale of abstraction versus the richness of being. Chicago: University of Chicago Press.

Giere, R. N. 2016. Feyerabend's perspectivism. Studies in History and Philosophy of Science Part A 57: 137-141. doi:10.1016/j.shpsa.2015.11.008

Godfrey-Smith, P. 2009. Darwinian populations and natural selection. Oxford: Oxford University Press.

Goertzen, J. 2007. Convergent pluralism and the unity-disunity debate in psychology. History and Philosophy of Psychology Bulletin 19(1): 11-16.

Heller, L. 2016. Between relativism and pluralism: Philosophical and political relativism in Feyerabend's late work. Studies in History and Philosophy of Science Part A, 57: 96-105.

Lloyd, E. A. 1997. Feyerabend, Mill, and pluralism. Philosophy of Science 64: S396-S407.

Manchak, J. 2021. On Feyerabend, General Relativity, and 'Unreasonable' Universes. In: Interpreting Feyerabend: Critical papers. Cambridge: Cambridge University Press.

Mill, J. S. 1961. The philosophy of John Stuart Mill: Ethical, political, and religious. M. Cohen (ed.) New York: Modern Library.

Mitchell, S. D. 2002. Integrative Pluralism. Biology and Philosophy 17: 55-70.

Munévar, G. 2002. Critical notice: conquering Feyerabend's Conquest of abundance. Philosophy of Science 69(3): 519-535.

Neto, J. R. M. 1991. Feyerabend's scepticism. Studies in History and Philosophy of Science Part A 22(4): 543-555. 
Oberheim, E. 2012 [2006]. Feyerabend's philosophy (2nd ed. Vol. 73). Berlin, Boston: Walter de Gruyter.

Oberheim;, E., \& Hoyningen-Huene, P. 2018. The Incommensurability of Scientific Theories. In: E. N. Zalta (ed.), The Standard Encyclopedia of Philosophy. Stanford: Metaphysics Research Lab, Stanford University.

Pepper, S. C. 1942. World hypotheses: A study in evidence (Vol. 31). Berkeley, CA: Univ of California Press.

Popper, K. R. 1959. The Logic of Scientific Discovery. New York: Basic Books, Inc.

Popper, K. R. 1972. Objective knowledge; an evolutionary approach. Oxford: Clarendon Press. Preston, J. 1997. Feyerabend: philosophy, science and society. Cambridge, MA: Polity press.

Preston, J. 2000. Science as supermarket. The Worst enemy of science, 80-101.

Preston, J. 2020. Paul Feyerabend. In: E. N. Zalta (ed.), The Stanford Encyclopedia of Philosophy (Fall 2020 ed.). https://plato.stanford.edu/archives/fall2020/entries/feyerabend. Metaphysics Research Lab, Stanford University.

Richards, R. J., \& Ruse, M. 2016. Debating Darwin. Chicago: University of Chicago Press.

Ruphy, S. 2011. From Hacking's plurality of styles of scientific reasoning to "Foliated" pluralism: A philosophically robust form of ontologico-methodological pluralism. Philosophy of Science 78(5): 1212-1222.

Ruphy, S. 2017. Scientific pluralism reconsidered: A new approach to the (dis) unity of science. Pittsburgh: University of Pittsburgh Press.

Ruse, M. 1999. The Darwinian revolution - science red in tooth and claw. (2nd ed.) Chicago: University of Chicago Press.

Shaw, J. 2016. Pluralism, pragmatism and functional explanations. Kairos. Journal of Philosophy \& Science 15(1): 1-18.

Shaw, J. 2017. Was Feyerabend an anarchist? The structure(s) of 'anything goes'. Studies in History and Philosophy of Science part A 64: 1-11.

Tambolo, L. 2007. Il "pluralismo libertario" di Feyerabend. Rivista di filosofia 98(3): 385-416.

Tambolo, L. 2015. A tale of three theories: Feyerabend and Popper on progress and the aim of science. Studies in History and Philosophy of Science 5: 33-41.

\section{Notes}

${ }^{1}$ We will come back to this later, but for now it is enough to say that, to Feyerabend, universal theory is a form of non-instantiated theory, as heliocentrism or geocentrism, and its main aspect is the cosmological nature with implications on "at least some aspects of everything there is." (1965b, p.224, fn.5).

${ }^{2}$ About this supposedly controversial expression, we agree with Farrell that when he asked "is Feyerabend's anarchism really anarchism, in the usual sense of the word? [...]. Feyerabend's anarchism does not imply chaos and complete disorder. [...]. Well, that isn't really anything goes: being adaptable and inventive is consistent with an ordered life-style and thought." (2003, p.65). He finishes the question saying that "I would want to say that Feyerabend's 'anarchism', when put into the context of his reductio, is not really an anarchism at all.” (2003, p.69). 
${ }^{3}$ We use this form of description, instead of the principle of proliferation and principle of tenacity, separately, not to make them look the same, but in order to highlight their mutual necessity. For more on this, see Shaw (2017). Therefore, it is important to highlight, as encouraged by one of the reviewers, that those principles are not the same idea (1981 [1970], pp.143-44). So, to make this even clear, we should not use principles of proliferation-tenacity in plural. They are only mutually complementary, let us say, proliferation without tenacity is blind and tenacity without proliferation is empty. Moreover, we used 'principles' in plural to make clear that they are not one principle

${ }^{4}$ Feyerabend's philosophy has a large variety of features, and most of them only make sense when taken collectively. We will focus only on proliferation-tenacity, and for the sake of the objectivity of the paper, we expect to let some doors open, as the debate about incommensurability, pluralistic model test, experience, and counterinduction.

${ }^{5}$ About these aspects, he says in "Consolation for the specialist": "Tenacity: this means that one is encouraged not just to follow one's inclinations, but to develop them further, to raise them" (1981 [1970], pp.143-44).

${ }^{6}$ As suggested by one of the reviewers, it is important to make clear how our proposal is different from the incommensurability thesis. The answer depends on how one reads that thesis. Considering some interpretations of Feyerabend's later version of the incommensurability thesis, which touches basically world-view, actions, attitudes, thoughts, language, perception, cultures, and theories (Oberheim; \& Hoyningen-Huene 2018), it is noticeable how, as argued in this paper, our proposal is not the same thing as the incommensurability thesis, but the foundation of it. By itself, the incommensurable thesis is an effect, which says nothing about the aspects that we highlighted in the Divergent proliferation-tenacity thesis. Moreover, given the fact that the later thesis of "incommensurability is difficult to explicitly define" (2018), this suggestion of the reviewer called the attention to the fact that our proposal is not only aligned with this later interpretation of the incommensurability, but it also helps to clarify it.

${ }^{7}$ To more about this, see Chang's paper "The coherence of Feyerabend's pluralist realism" (2021).

${ }^{8}$ About this aspect of inconsistency, according to Farrell (2003), "Feyerabend did not draw the line sharply between theories which are merely inconsistent, and those which are incommensurable. That may have created the impression that simple inconsistency between two theories was enough to create incommensurability" (2003, p.89). Inconsistency, like many other elements, could take place between two theories without necessarily a clash between their realities. This does not happen with incommensurability, at least not from a realistic interpretation of theories.

${ }^{9}$ We could ask for the help of Feyerabend's metaphor to clarify this point. A river that crosses two countries may be subdivided by their boundaries, but "this does not make it a discontinuous entity." (1993, p.148).

${ }^{10}$ Both reviewers pointed out the relevance of this issue. One of them asked us to do a deeper analysis of this relationship. We agree with them about the relevance of the matter, and we made some adjustments. However, a deeper and a more appropriate analysis of it would require space that we do not have here. But I will treat the question in a future paper dedicated to it.

${ }^{11}$ It is important to highlight here that such a proposal does not replace all advances made 
to understand Feyerabend's philosophy. Actually, the way we see it, our proposal unites all interpretations that already exist under what we believe to be a minimal common ground that can be used to better avoid mistakes and push the researchers forward. Paraphrasing a philosopher, our work is like a kaleidoscope, the pieces were out there, all we did was shake them up to have something different (Ruse 1999).

${ }^{12}$ The reader should remember that, since proliferation and tenacity go together, criticism is a fundamental part of the notion of tenacity. We claim that when Feyerabend talks about proliferation coupled with criticism, he is thinking of the interplay between proliferation and tenacity.

13"Darwinian population in the minimal sense is a collection of causally connected individual things in which there is variation in character, which leads to differences in reproductive output (differences in how much or how quickly individuals reproduce), and which is inherited to some extent" (Godfrey-Smith 2009, p.130).

${ }^{14}$ Darwins's evolutionary theory is more complex than this. For instance, do Darwinian populations reproduce as much as the individuals? How about the time length of reproduction in a threatening environment and how it affects the arising of divergent characteristics? Darwin emphasized that his evolutionary theory is a long process, so evolution is abstract in the sense that the inevitability of evolution follows only under the fulfillment of certain preconditions (Godfrey-Smith 2009). The same applies to the principle of divergence, Feyerabendian or not.

${ }^{15}$ Just to highlight, Feyerabend explicitly says that he was not focused on "advanc[ing] knowledge" (1993, p.xii). However, when he says this, the claim was made under the question of what is more important in a dispute between humanitarian and intellectual values. So in this scenario, his answer remains the same. In our scenario, the question is not under the same constraints, so it is valid to claim that he cares about the advance of knowledge.

${ }^{16}$ This subject brings up a discussion about the adequacy of Feyerabend's choice of analogy from Darwin's theory of evolution and natural selection, and whether or not he was mistaken for making that comparison due to his tenacity principle. In the introduction of Philosophical Papers- $v 3$ (1999), John Preston briefly talked about the inadequacy of such analogy between proliferation and tenacity with the evolutionary model (1999, p.6). He argues that we cannot retain species in the same way that tenacity recommends. Although we agree with Preston that such an inadequacy was a real concern, in the present day we also think that our proposal gives an answer of why such an inadequacy is avoidable. Accordingly, as we explained, Feyerabend's definition of tenacity encourages us to criticize and develop alternatives, and not simply retain them. Thus, in Against Method, he says that on different levels some of those alternatives will succeed and other will decay (1993, p.270). Second, his analogy with the evolutionary model is clearly driven by the principle of proliferation and divergence, not by tenacity. He says that tenacity was put forth by dialectical materialists (such as Lenin, Engels and Trotsky) only to avoid idealistic "flights of fancy" (1981 [1970], p.144). In other words, the association of the interplay of proliferation-tenacity with Darwin's theory is only in respect to the proliferation aspect of that pair, not to the whole thing.

${ }^{17}$ It is interesting to notice that the assertion in the idea of an ocean of alternatives, as Tambolo remarked, although introduced in 1965, appeared in previous papers since 1962 (Tambolo 2015, p.38, fn 9). This is important because this conception of progress stayed with Feyerabend throughout his career as much as some of its consequences. 
${ }^{18}$ One of the reviewers called our attention to the fact that before Conquest of Abundance (1999), Feyerabend does not posit any metaphysical view, meaning that monism is theoretically possible. However, we think that it depends on what the reviewer meant by metaphysics. If we think in metaphysics as a philosophical strand of investigation concerned with the nature of what exists, the realities, and our ways to access them, then we can see a metaphysical view before Conquest of Abundance (1999). In Against Method (1993), just to point one case, Feyerabend said that "Pluralism of theories and metaphysical views is not only important for methodology, it is also an essential part of a humanitarian outlook" (1993, p. 38). We can see similar positions in papers such as "Problems of empiricism" (1965) and "How to be a good empiricist" (1969).

${ }^{19}$ For a discussion on a similar matter, see Manchak's "On Feyerabend, General Relativity, and 'Unreasonable' Universes" (2021).

${ }^{20}$ About this skeptical issue, whether or not Feyerabend is skeptic, we remind the reader that Feyerabend sent a letter replying to Athanasopoulos (post marked on the 13th of March 1992), in which he says that he is not sure about this question and that he found it "somehow misleading". Athanasopoulos acknowledged that there is no way to classify Feyerabend strictly as a skeptic. Nonetheless, Feyerabend said that instead of asking whether he is a skeptic himself, we should look for overlaps between his view and skepticism, and "the reason is because I do not have a fixed view - I am as it were Heraclitean Sceptic" (Athanasopoulos 1994, p.23).

${ }^{21}$ About the notion of concrete cases or circumstances he says in chapter twenty of Against Method that "The arguments supporting my complaint were quite good they are the arguments summarized in Chapter 3 - but it was suddenly clear to me that imposed without regard to circumstances they were a hindrance rather than a help: a person trying to solve a problem whether in science or elsewhere must be given complete freedom and cannot be restricted by any demands, norms, however plausible they may seem to the logician or the philosopher who has thought them out in the privacy of his study." (1993, p.262, underlines added).

${ }^{22}$ As Shaw (2017, p.5) correctly pointed out, since attractiveness and fruitfulness are items that the principle of tenacity used to evaluate our theories, a problem that arises is the lack of definition of these items in the "Outline of a pluralistic theory of knowledge and action" paper (1968), and elsewhere, to help us with the task of understanding what these two items entail. We hope to clear things up a bit more.

${ }^{23}$ These difficulties can be internal or external to the theory, as Feyerabend seems to indicate in the same paper.

${ }^{24}$ In Against Method (1993), Feyerabend clarifies that he thinks that things like accepted and acceptable, use and usable theories represent different situations. For instance, he thinks that if some alternative view shares instances with the already accepted view, then these instances do not "show that such an alternative is acceptable; and even less do they show that it should be used." (1993, p. 25, italics on the original). He also does not think that pluralism must create already accepted theories. Rather, coupling proliferation and tenacity, if needed even using propaganda as "part of rationality" (1993, p.76, fn. 22), can result in acceptable proposals. The reason is "I add that science contains ingredients that occasionally need such 'trickery' to become acceptable". (1993, p.76, fn.22, italic added). By the way, this trickery strategy does not work alone, it has to be coupled with any "intellectual reasons he [the 
scientist] has to offer" (1970, p.313, brackets added).

${ }^{25}$ Feyerabend argues against a Chinese astrophysicist Fang Lizhi, who claimed a cosmological principle of the universe, which allegedly, allows him to claim for a universal epistemological basis for science, followed by universal standards of human rights (1999, p.242). As an example of the argument, Feyerabend addresses only the 'totalitarian aspect' of Fang's view. He states that "abstract celebrations of freedom are not my cup of tea" (1999, p.243), but more concrete ones. Precisely for this reason he does go further, for he does not want to interfere in the political situation of China, which he is not personally familiarized(1999).

${ }^{26}$ Feyerabend uses rejection in a sense that does not mean elimination/deletion, but rather a temporary setback. This is part of the constitution of the proliferation game (1981b, p.140; 1999 [1980], p.214). It is not rare that a theory that was once rejected becomes accepted later. For instance, he says, "Relativity and quantum theory were rejected at once, and almost as a matter of course, for being idle speculation." (1993, p 255). Elimination would be a complete exclusion of theories (which is something that Feyerabend does not think of as performed by science). In Feyerabend's view, theories can be epistemically compared, and even considered triumphant or defeated, because he is not philosophically relativist or skeptic. His pluralism are willing to advance knowledge, only that not under the obliteration of the defeated efforts. After all, we are limited beings and our triumphs could be nothing but a miserable error.

\section{Acknowledgments}

First and foremost I thank to Jamie Shaw for providing crucial and insightful guidance. I thank to two anonymous referees of the manuscript, who made it much, much better. The people of the Center of philosophy of science of the University of Pittsburgh, and to Jagdish Hattiangadi for the period of learning at York University. I thank the insights from the GEfficientia group. Finally, thanks to the Federal University of Reconcavo of Bahia. 